\title{
Combined Printing and Creation of A "Host Guest" Functional Textile for Depositing Fragrance
}

\author{
J.I. Abd -El Thalouth ${ }^{*}$, A.H. Naser and N. G. Gaber
}

Faculty of Applied Arts, Helwan University, Cairo, Egypt.

\begin{abstract}
7 THE EFFECT of chemical modification of cotton and cellulosic portion of its blend with polyester with reactive cyclodextrin R$\mathrm{CD}$ on its printability with reactive dye as well as its ability to keep fragrance was thoroughly investigated. The results obtained indicate that, the extent of reaction expressed as $\% \mathrm{~N}$ increases by increasing $\mathrm{R}$ $\mathrm{CD}$ concentration. The K/S of R-CD modified samples is relatively higher than the untreated samples for both cotton and its blend with polyester, while the overall colour fastness properties are nearly the same. In case of incorporation of R-CD to the printing paste, the K/S increases as the amount of R-CD increases from 50 to $75 \mathrm{~g} / \mathrm{Kg}$ printing paste, on increasing the amount of R-CD to $100 \mathrm{~g}$ the opposite holds true. The effect of treatment with different perfume oils viz. vanelline, rose, jasmine and sandal on ability of the treated fabrics to keep fragrance upon storing for $2,20,30,37$ and 90 days was also investigated. It was found that the ability to keep fragrance increases by increasing the extent of reaction expressed as $\% \mathrm{~N}$ and decreases by increasing storing time (up to 3 months) and it depends on the kind of the perfume oil, where it can be arranged according to the order: sandal $>$ jasmine $>$ rose $>$ vanelline oil. Application of the obtained results was also done for scented ladies wear in innovation designs coloured with bifunctional reactive dye.
\end{abstract}

Keywords: R-CD, Cotton, Cotton/polyester, Printing and Perfumed textile.

The most important development in textiles is the design of innovative fibers and fabrics that have got physiological and function benefits. Aromatherapy is the use of fragrances or volatile substances to cure, miligate or prevent diseases, infection and indisposition by means only of inhalation ${ }^{(1-4)}$. The combination of aromatherapy with textiles can allow the wearer to enjoy the therapeutic effects, or simply the fresh smell ${ }^{(5)}$. Perfuming of textiles can be achieved during either treatment or care. Incorporation of perfume retention agents during treatment such as elastomer latex/synthetic resin emulsions ${ }^{(6)}$, thermoplastic microcapsules ${ }^{(7)}$, cyclodextrine $^{(8)}$ and coating compositions ${ }^{(9)}$ was reported to bring about textile goods that can release fragrance over a long period of time ${ }^{(10)}$.

Cyclodextrine (CD) is cyclic oligosaccharides usually composed of six, seven or eight D-gluopyranoside units a 1,4-glucosidic bond as shown in the following

*Corresponding author : Telephone: +20233912312. Mobile: +201112943343.

E-mail:jackyibm@yahoo.com 
figure $^{(11,12)} \cdot \alpha-C D, \beta-C D$ and $\gamma-C D$ posess six, seven and eight glucopyranoside units, respectively and produced from enzymatic degradation of starch. They have been used primarily in pharmaceutical, food and cosmetic industries, awing to the ability to form inclusion complexes with various organic compounds as well as their biodegradable and non-toxic properties ${ }^{(13)}$.

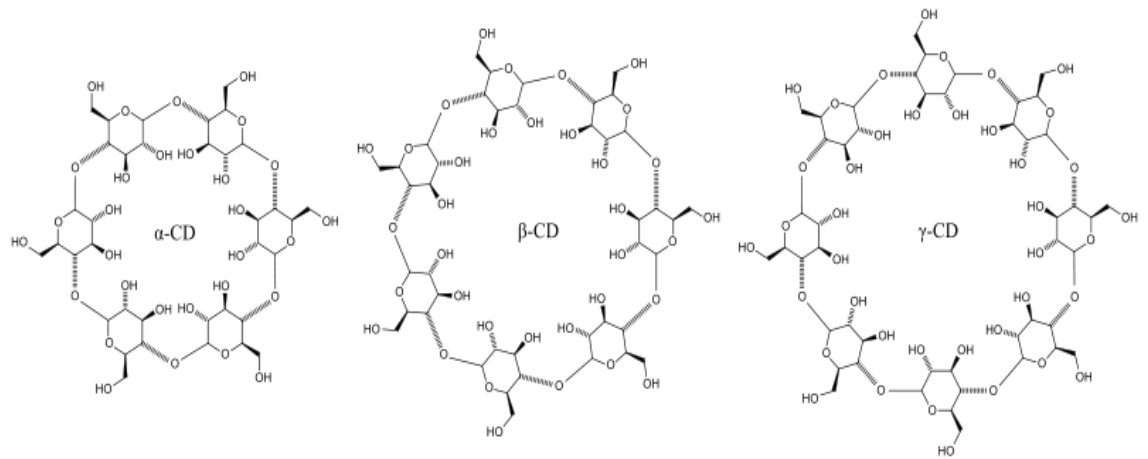

In textile industry, cyclodextrins have been classified as a new class auxiliary substances, acting as defoaming agents, dyeing aids and finishing agents ${ }^{(14)}$. Textile finishing involves treating a textile substrate mechanically or chemically in order to obtain the product having the desired aesthetic and functional properties for its end use, resulting in greater added value.

The objective of the present study is to anchor the reactive $\beta$-Cyclodextrin on cellulosic fibre or the cellulosic portion of cotton/ polyester blend with the bifunctional reactive dye, to create a "host guest" functional textile for depositing fragrance.

\section{Experimental}

Materials

Substrates

- Cotton fabrics: Mill desized, kier boiled and bleached cotton fabric (120 $\mathrm{g} / \mathrm{m}^{2}$ ) supplied by Misr Company for Spinning and Weaving, Mehalla El- Kubra, Egypt.

- Cotton/polyester blend (47:53\%) $\left(126 \mathrm{~g} / \mathrm{m}^{2}\right)$ supplied by El-Ameria for Spinning and Weaving Alexandria, Egypt.

Dyestuffs

- Reactive dye: Bi-functional reactive dye under the commercial name Drimaren Red CL-5B supplied by Clarinet, Cairo, Egypt.

Chemicals

- Reactive cyclodextrin (R-CD) contains reactive mono- chlorotriazine ring supplied by Clariant, Cairo.

Egypt. J. Chem. 59, No.1 (2016) 
- Sodium alginate of medium viscosity under the commercial name Daico thickener RE supplied from Daico Chemical Industry S.A.E. Cairo, Egypt.

- Perfuming oils: four different artificial commercial perfuming oils namely rose, jasmine, vanillin and sandal oils were purchased from Egyptian Market, AlAzhar, Cairo.

- Other chemicals: Urea and sodium bicarbonate were of laboratory grade chemicals. Commercial ethyl alcohol and non-ionic detergent were also used.

Methods

Treatment with $R-C D$

The conventional pad-dry-thermofixation method was applied. The pad bath containing R-CD and the catalyst (sodium bicarbonate) was prepared as follows: A small amount of water was added to R-CD and the resulting solution was warmed up until complete dissolution occurred. The solution was then cooled down at room temperature and the pad bath concentration was adjusted along with concurrent addition of the catalyst (sodium bicarbonate $20 \mathrm{~g} / \mathrm{l}$ ). The fabric was padded in the bath twice to a wet pick up of $100 \%$. The treated fabric was dried in an oven for $13 \mathrm{~min}$ at $60-70^{\circ} \mathrm{C}$ then subjected to thermofixtion at $150^{\circ} \mathrm{C}$ for $7 \mathrm{~min}$. Different concentrations of R-CD viz. 50, 75 and $100 \mathrm{~g} / \mathrm{l}$ were used to obtain different extents of reaction.

Preparation of the printing paste

Printing paste containing reactive dye was prepared according to the following recipe :

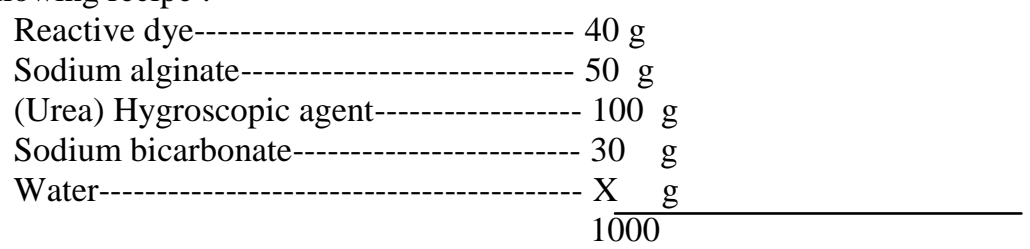

The thickener was soaked in a small amount of water overnight at room temperature before commencing preparation of the printing paste.

The dye was first mixed with urea and some hot water. Thorough stirring of this mixture was performed to homogenize the solution. This solution was then poured on the thickener suspension and the whole mixture was thoroughly stirred with solution of the bicarbonate. Finally the total weight of the whole paste was adjusted to one kilogram with addition of necessary amount of water.

- Printing technique: The printing paste was applied to either cotton or cotton/polyester blend as per the flat screen printing. After printing, the printed goods were air dried then subjected to fixation via steaming at $100-103^{\circ} \mathrm{C}$ for 15 min followed by washing according to the standared technique used for washing reactive dyes. 
Treatment with perfume oil

Fabric samples were cooled to ambient temperature, then padded in an alcoholic solution of perfume oil $(300 \mathrm{~g} / \mathrm{l}$ ethanol $95 \%)$ to a wet pick up of $100 \%$, then dried at ambient conditions for $2 \mathrm{hr}$ before testing. The samples were tested after conditioning for $12 \mathrm{hr}$ at standard conditions.

\section{Analysis and measurements}

-Nitrogen cotent was determined by the Cole and Parks modifications of semimicor Kjeldahl method ${ }^{(15)}$.

-The colour strength $(\mathrm{K} / \mathrm{S})^{(16)}$, and the overall colour fastness properties, i.e. to washing, to perspiration and to rubbing were measured according to standard technique ${ }^{(17)}$

-The \% loss in weight gained was estimated by calculating, first the weight gained due to padding in the alcoholic solution of the perfume oil, as follows:

Weight gained $=(\mathrm{A}-\mathrm{B})$

where $\mathrm{A}$ and $\mathrm{B}$ are the weights of the fabric after and before padding in the perfume oil solution.

$$
\% \text { loss in weight }=\{(\mathrm{A}-\mathrm{B})-(\mathrm{B}-\mathrm{C})\} \times 100
$$

$(\mathrm{A}-\mathrm{B})$

where $\mathrm{C}$ is the weight of fabric after storage.

\section{Results and Discussion}

As previously mentioned the aim of the present work is to improve the printability of cellulosic fabrics and its blend with polyester towards reactive dye and also to acquire it an ability to keep perfume fragrances upon storing more than 3 months. To achieve the required goal, both cotton and the cellulosic portion of its blend were subjected to react with R-CD via either pretreatment or incorporation of $\mathrm{R}-\mathrm{CD}$ in the printing paste as follows:

Modification with $R-C D$

As an electrophilic compound, R-CD reacts in the presence of alkali with nucleophilic groups such as the hydroxyl groups of cellulose (cell), as shown in the following equation:

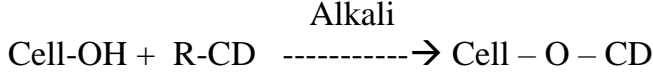

The reaction involves covalent binding to the cellulose and therefore can be categorized in the reactions that induce chemical modification of cellulose. 
Hence samples of cotton or cotton/ polyester blend were allowed to react with different concentrations of R-CD (50,75 and $100 \mathrm{~g} / \mathrm{l})$ (Table 1) in presence of sodium bicarbonate according to the procedure described in the Experimental section.

TABLE 1. Dependence of the extent of reaction $(\% \mathrm{~N})$ of $\mathrm{R}-\mathrm{CD}$ of both cotton and its blend on R-CD concentration.

\begin{tabular}{|c|c|c|}
\hline \multirow{2}{*}{$\begin{array}{c}\text { R-CD concentration } \\
(\mathbf{g} / \mathbf{l})\end{array}$} & Cotton & \% \\
\cline { 2 - 3 } & 0.15 & 0.04 \\
\hline 50 & 0.30 & 0.05 \\
\hline 75 & 0.50 & 0.07 \\
\hline 100 & & Cotton/polyester blend \\
\hline
\end{tabular}

Table 1 represents the dependence of the extent of reaction (expressed as \% $\mathrm{N})$ of R-CD with cotton cellulose and with the cellulosic portion of cotton/polyester blend on the concentration of R-CD.

It is clear from Table 1 that the extent of reaction between cellulose hydroxyl and R-CD, expressed as $\% \mathrm{~N}$, increases from 0.15 to 0.5 in case of pure cotton and from 0.04 to 0.07 in case of cotton/polyester blend when the R-CD concentration increases from 50 to $100 \mathrm{~g} / \mathrm{l}$. This significant increase in the $\% \mathrm{~N}$ could be interpreted in terms of greater availability of R-CD in the proximate of the hydroxyl groups of cotton cellulose. It is understandable that the cellulose hydroxyl groups are immobile and hence reaction of these hydroxyl groups would rely on availability of R-CD molecules in their vicinity. A point which is justified at higher R-CD concentration. The decrease in the $\% \mathrm{~N}$ of cotton/polyester blend compared with pure cotton is expected since in case of the blend, only the cellulosic portion could react with R-CD.

\section{Printing R-CD modified fabrics}

The aforementioned R-CD modified cotton and cotton/polyester blend samples were printed with a bifunctional reactive dye namely Drimaren red CL5B. After printing, drying, fixation, washing and drying. The dried samples were assessed for K/S and overall colour fastness properties. Table 2 represents the effect of R-CD concentration on the K/S and overall colour fastness properties for modified cotton and its blend with polyester.

It is clear from the data of Table 2 that the K/S of R-CD modified cotton or cotton/polyester fabric samples is relatively higher than the untreated fabric samples irrespective of the printed fabric. It is also clear that as the $\% \mathrm{~N}$ increases the K/S of the printed fabric increases too. The increase in K/S by modification of cotton with R-CD may be due to one or more of the following reasons: (1) The increase in the number of free hydroxyl groups present in R-CD itself, (2) the inclusion of the dye molecules in the cone-shaped of R-CD molecules, and (3) the physicochemical changes of R-CD modified cotton fabrics. 
Table 2 also reveal that the colour fastness properties for rubbing, washing and perspiration of R-CD modified cotton or cotton/polyester blend samples are very comparable with those obtained in case of the unmodified cotton samples. This implies that presence of cyclodextrine moieties in the molecular structure of printed cotton or its blend does not detract from its overall colour fastness properties.

TABLE 2. Effect of the concentration of R-CD on the K/S and on overall colour fastness properties of cotton and cotton/polyester blend printed with Drimarene red CL-5B.

\begin{tabular}{|c|c|c|c|c|c|c|c|c|c|c|c|}
\hline \multirow{4}{*}{$\begin{array}{c}\text { Printed } \\
\text { fabric }\end{array}$} & \multirow{4}{*}{$\begin{array}{l}\text { Conc. } \\
\text { Of R- } \\
\text { CD(g/l) }\end{array}$} & \multirow{4}{*}{$\mathbf{K} / \mathbf{S}$} & \multirow{4}{*}{$\% \mathbf{N}$} & \multicolumn{8}{|c|}{ Colour fastness properties to: } \\
\hline & & & & \multicolumn{2}{|c|}{ Washing } & \multicolumn{2}{|c|}{ Rubbing } & \multicolumn{4}{|c|}{ Perspiration } \\
\hline & & & & \multirow[t]{2}{*}{ St. } & \multirow[t]{2}{*}{ Alt. } & \multirow[t]{2}{*}{ Wet } & \multirow[t]{2}{*}{ Dry } & \multicolumn{2}{|c|}{ Acidic } & \multicolumn{2}{|c|}{ Alkaline } \\
\hline & & & & & & & & St. & Alt. & St. & Alt. \\
\hline \multirow[t]{4}{*}{ Cotton } & Untreated & 6.96 & 0 & $3-4$ & 4 & 3 & 4 & 4 & 4 & 4 & 4 \\
\hline & 50 & 7.06 & 0.15 & $3-4$ & 4 & 3 & 4 & $3-4$ & 4 & $3-4$ & 4 \\
\hline & 75 & 7.28 & 0.30 & 4 & 4 & 3 & 4 & 4 & 4 & 4 & 4 \\
\hline & 100 & 8.10 & 0.50 & $3-4$ & 4 & $3-4$ & $4-5$ & 4 & 4 & 4 & 4 \\
\hline \multirow{4}{*}{$\begin{array}{l}\text { Cotton/ } \\
\text { Polyester }\end{array}$} & Untreated & 2.03 & 0 & 3 & $3-4$ & $3-4$ & $4-5$ & 4 & 4 & 4 & 4 \\
\hline & 50 & 2.68 & 0.04 & 4 & 4 & 3 & 4 & 4 & 4 & 4 & 4 \\
\hline & 75 & 2.76 & 0.05 & 4 & 4 & 3 & 4 & 4 & 4 & 4 & 4 \\
\hline & 100 & 2.88 & 0.07 & $3-4$ & 4 & $3-4$ & $4-5$ & 4 & 4 & 4 & 4 \\
\hline
\end{tabular}

\section{Ability of coloured $R$-CD modified fabrics to keep fragrance}

The effect of chemical modification, of cotton and of the cellulosic portion of its blend with polyester, with different concentrations of R-CD followed by printing with reactive dye on their ability to keep fragrance upon storing for relatively long period expressed as \% loss in weight gained was investigated. This was done via treatment with vanelline, rose, jasmine and sandal oils according to the procedure aforementioned in the Experimental section. The data obtained are given in Fig. 1-4, (where A-For cotton and B- For its blend) for fabrics treated with vanelline, rose, jasmine and sandal oils and stored for 7, 20, $30,37,60$ and 90 days. 

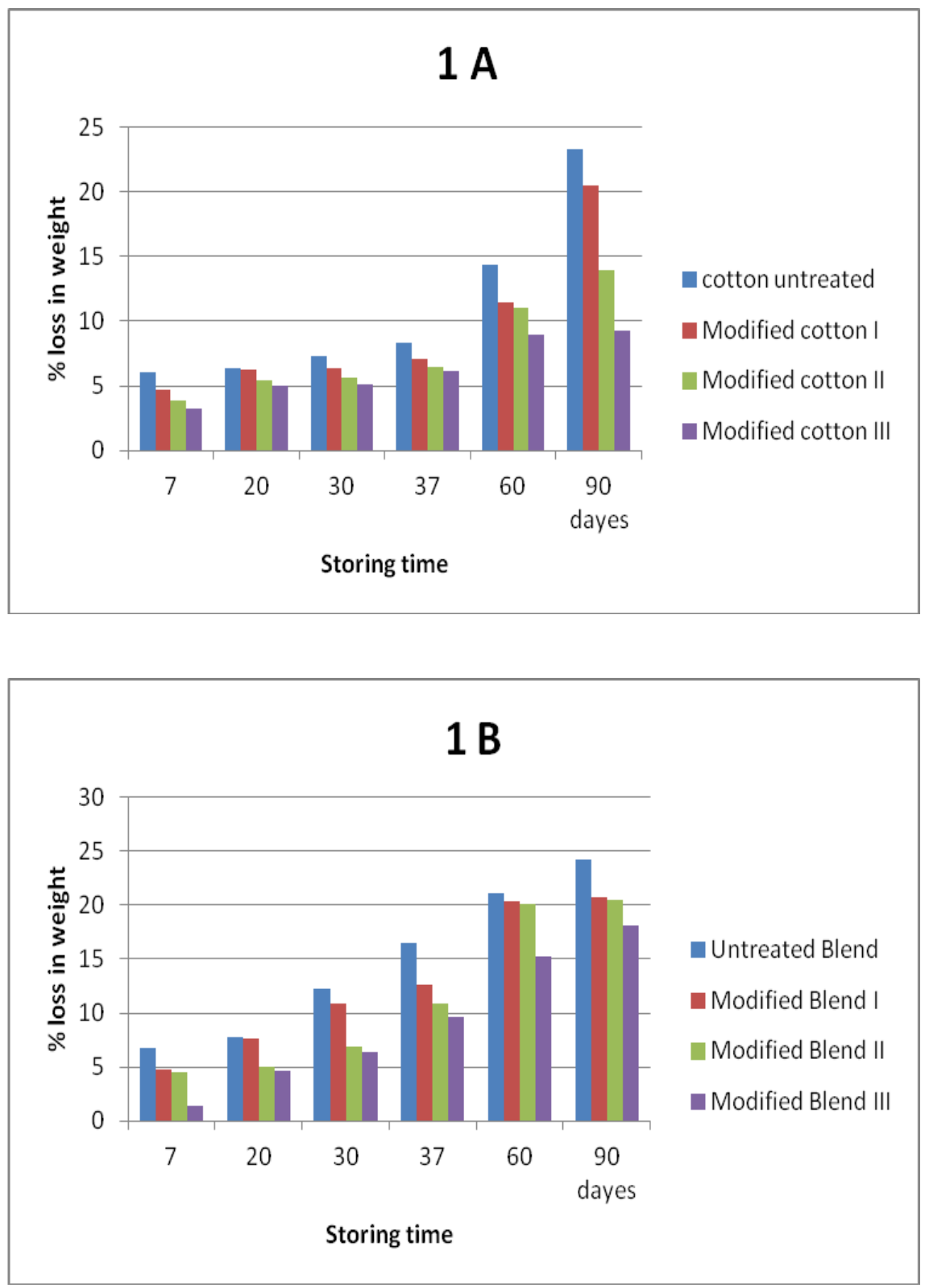

Fig. 1 (A-B). Effect of modification of cotton (A) and cotton /polyester blends (B) with different concentrations of R-CD followed by treatment with vanelline on their ability to keep fragrance upon storing. 

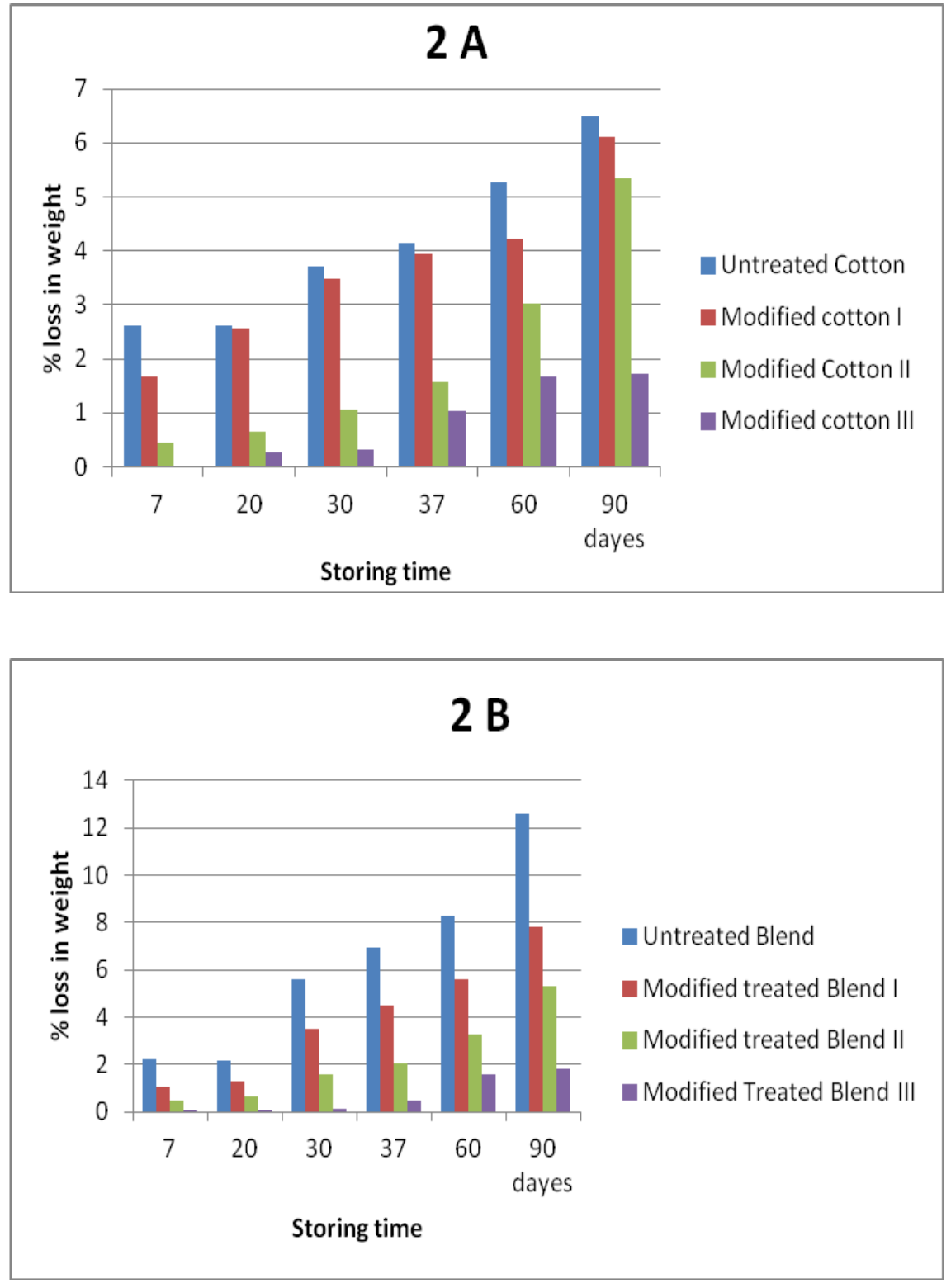

Fig. 2 (A-B). Effect of modification of cotton (A) and cotton /polyester blends (B) with different concentrations of R-CD followed by treatment with sandal oil on their ability to keep fragrance upon storing. 

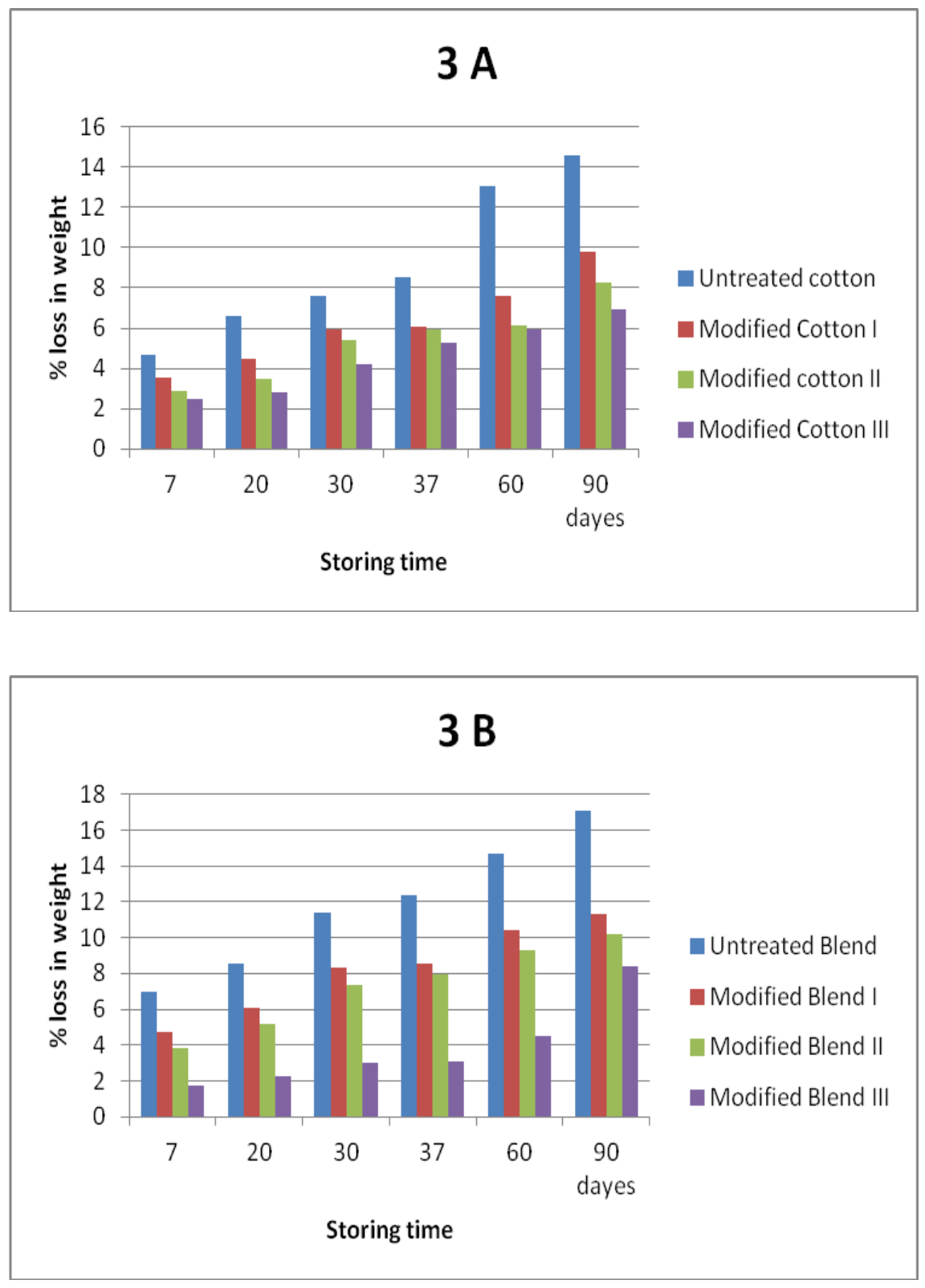

Fig. 3 (A-B). Effect of modification of cotton (A) and cotton /polyester blends (B) with different concentrations of R-CD followed by treatment with rose oil on their ability to keep fragrance upon storing. 

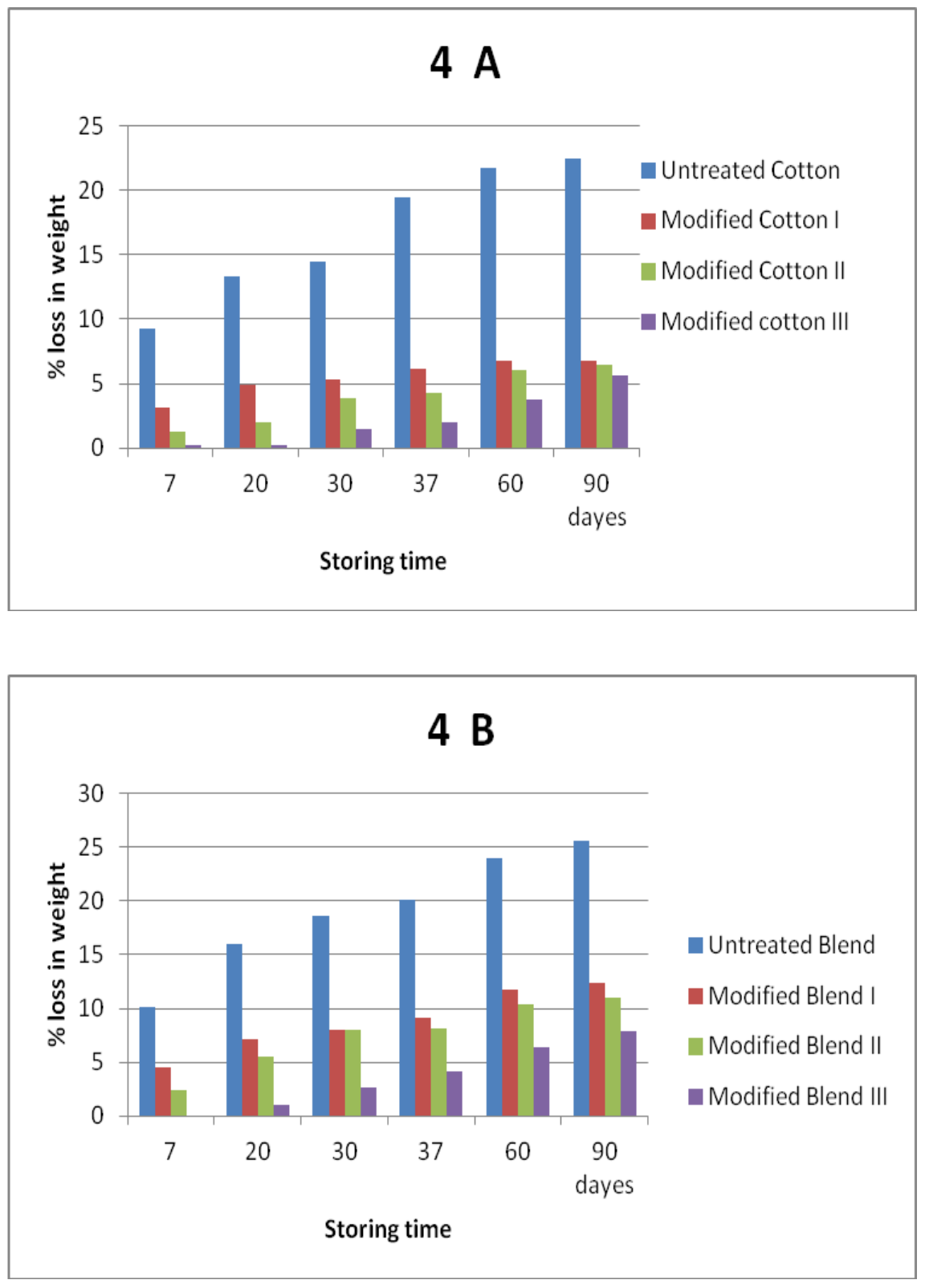

Fig. 4 (A-B). Effect of modification of cotton (A) and cotton /polyester blends (B) with different concentrations of R-CD followed by treatment with Jasmine oil on their ability to keep fragrance upon storing. 
Generally speaking, it is clear from the data (Fig. 1(A-B) - 4(A-B)) that the ability of the investigated fabrics to keep fragrance upon storing up to 3 months, depends on: (a) nature of the fabric, (b) degree of modification expressed as $\% \mathrm{~N}$, (c) kind of the perfume used, and (d) storing time.

Furthermore, it is clear from the data that the R-CD modified fabrics has a higher ability to keep fragrance compared with the untreated fabric this may be due to the inclusion of the perfume molecules in the cone-shaped of the R-CD and also on the physicochemical changes of R-CD modified cotton fabrics.

Figures $1-4$ show the effect of using different perfume oils viz. vanelline, rose, jasmine and sandal on the ability of the treated fabrics to keep fragrance upon storing for 7,20,30,37,60 and 90 days. It is obvious that the ability to keep fragrance decreases by increasing storing time (up to 3 months) and it depends on the kind of the perfume oil, where it can be arranged according to the order sandal $>$ jasmine $>$ rose $>$ vanelline. The difference between the results obtained on using the aforementioned perfume oils may be due to the variation in their physico/chemical properties viz. molecular weight, boiling point.....etc.

\section{Effect of incorporating $R$-CD in reactive printing paste}

In order to save energy, cost and time the R-CD particles were incorporated directly in the printing paste at the same concentrations as previously used, i.e. 50,75 and $100 \mathrm{~g} / \mathrm{kg}$ printing paste. The obtained data of $\mathrm{K} / \mathrm{S}$ and overall colour fastness properties are illustrated in Table 3 .

TABLE 3. Effect of incorporation of different amounts of R-CD on the printing paste of Drimarene red CL-5B on both $\mathrm{K} / \mathrm{S}$ and overall colour fastness for printed cotton and cotton/polyester blend.

\begin{tabular}{|c|c|c|c|c|c|c|c|c|c|c|}
\hline \multirow{4}{*}{ Printed fabric } & \multirow{4}{*}{$\begin{array}{l}\text { Conc. } \\
\text { Of R- } \\
\text { CD }(g / l)\end{array}$} & \multirow{4}{*}{$\mathbf{K} / \mathbf{S}$} & \multicolumn{8}{|c|}{ Colour fastness properties to: } \\
\hline & & & \multicolumn{2}{|c|}{ Washing } & \multicolumn{2}{|c|}{ Rubbing } & \multicolumn{4}{|c|}{ Perspiration } \\
\hline & & & \multirow[t]{2}{*}{ St. } & \multirow[t]{2}{*}{ Alt. } & \multirow[t]{2}{*}{ Wet } & \multirow[t]{2}{*}{ Dry } & \multicolumn{2}{|c|}{ Acidic } & \multicolumn{2}{|c|}{ Alkaline } \\
\hline & & & & & & & St. & Alt. & St. & Alt. \\
\hline \multirow[t]{4}{*}{ Cotton } & Untreated & 6.96 & $3-4$ & 4 & 3 & 4 & 4 & $4-5$ & 4 & $4-5$ \\
\hline & 50 & 10.63 & $3-4$ & 4 & 3 & $4-5$ & $3-4$ & 4 & 4 & $4-5$ \\
\hline & 75 & 13.11 & $3-4$ & $4-5$ & $4-5$ & 4 & 4 & $4-5$ & 4 & $4-5$ \\
\hline & 100 & 11.46 & $3-4$ & 4 & 3 & $4-5$ & 4 & $4-5$ & 4 & $4-5$ \\
\hline \multirow{4}{*}{$\begin{array}{l}\text { Cotton/ } \\
\text { Polyester }\end{array}$} & Untreated & 2.03 & 3 & 4 & $3-4$ & $4-5$ & 4 & $4-5$ & 4 & $4-5$ \\
\hline & 50 & 4.37 & 4 & 4 & $3-4$ & $4-5$ & 4 & $4-5$ & 4 & $4-5$ \\
\hline & 75 & 5.00 & 4 & $4-5$ & $3-4$ & $4-5$ & 4 & 4 & 4 & $4-5$ \\
\hline & 100 & 4.69 & 4 & $4-5$ & $3-4$ & $4-5$ & 4 & $4-5$ & 4 & $4-5$ \\
\hline
\end{tabular}


It is clear from the data of Table 3, that there is an improvement in K/S in case of incorporation of $\mathrm{R}-\mathrm{CD}$ in the printing paste. Compared with their corresponding pretreated samples. But the highest $\mathrm{K} / \mathrm{S}$ was obtained at a concentration of $75 \mathrm{~g} / \mathrm{Kg}$ printing paste.

The increase in K/S in case of incorporating $\mathrm{R}-\mathrm{CD}$ directly to the printing paste is expected; since R-CD is a cone shaped particle contains three free hydroxyl groups. Hence, it can react easily with both cellulose and reactive dye and act as a bridge between cellulose and reactive dye molecules. Besides it can trap some reactive dye molecules inside its cone shape.

The current data reveal that the optimum concentration of R-CD in the printing paste to obtain the highest $\mathrm{K} / \mathrm{S}$ is $75 \mathrm{~g} / \mathrm{Kg}$ paste. Increasing the amount of R-CD is accompanied by a decrease in K/S. This statement holds true in both cases, i.e. in case of cotton or its blend with polyester. It seems that increasing the amount of R-CD up to $100 \mathrm{~g}$ decreases the mobility of both R-CD and reactive dye molecules and hence it is accompanied by a less availability of R-CD in the proximate of the hydroxyl groups of cotton cellulose. As a result the chance for reaction between cellulose hydroxyl groups and both $\mathrm{R}-\mathrm{CD}$ and reactive dyes decreases.

The effect of treating the samples (printed with reactive dye printing pastes containing different amounts of R-CD) with perfume oils was investigated. The results of the ability of the coloured samples to keep fragrance of perfume oils expressed as \% loss in weight are represented in Fig. 5 - 8 for using vanelline, sandal, rose and jasmine, respectively.

It is clear from the data of Fig. 5 - 8, that the \% loss in weight depends on : (a) the $\%$ of R-CD incorporated in the printing paste, (b) the kind of fragrances used, and (c) the time of storing.

It is also clear from the data that incorporating $75 \% \mathrm{R}-\mathrm{CD}$ in the reactive printing paste was the optimum to obtain the higher K/S as well as the highest ability to keep perfume oil fragrance upon storing.

It can be concluded that the ability to keep fragrance decreases by increasing storing time (up to 3 months) and increases by modification of cotton or cotton/polyester blend by reacting it with reactive cyclodextrine. However the magnitude of $\%$ loss in weight depends on nature of the perfume oil used as following the order: Sandal oil $>$ Jasmine oil $>$ rose oil $>$ vanellinee oil.

It is worthy to mention that this study was extended via entering aromatic scents property in evening fabrics for ladies. This increases the importance of these fabrics, as well as their artistic and applied value ${ }^{(18)}$. 

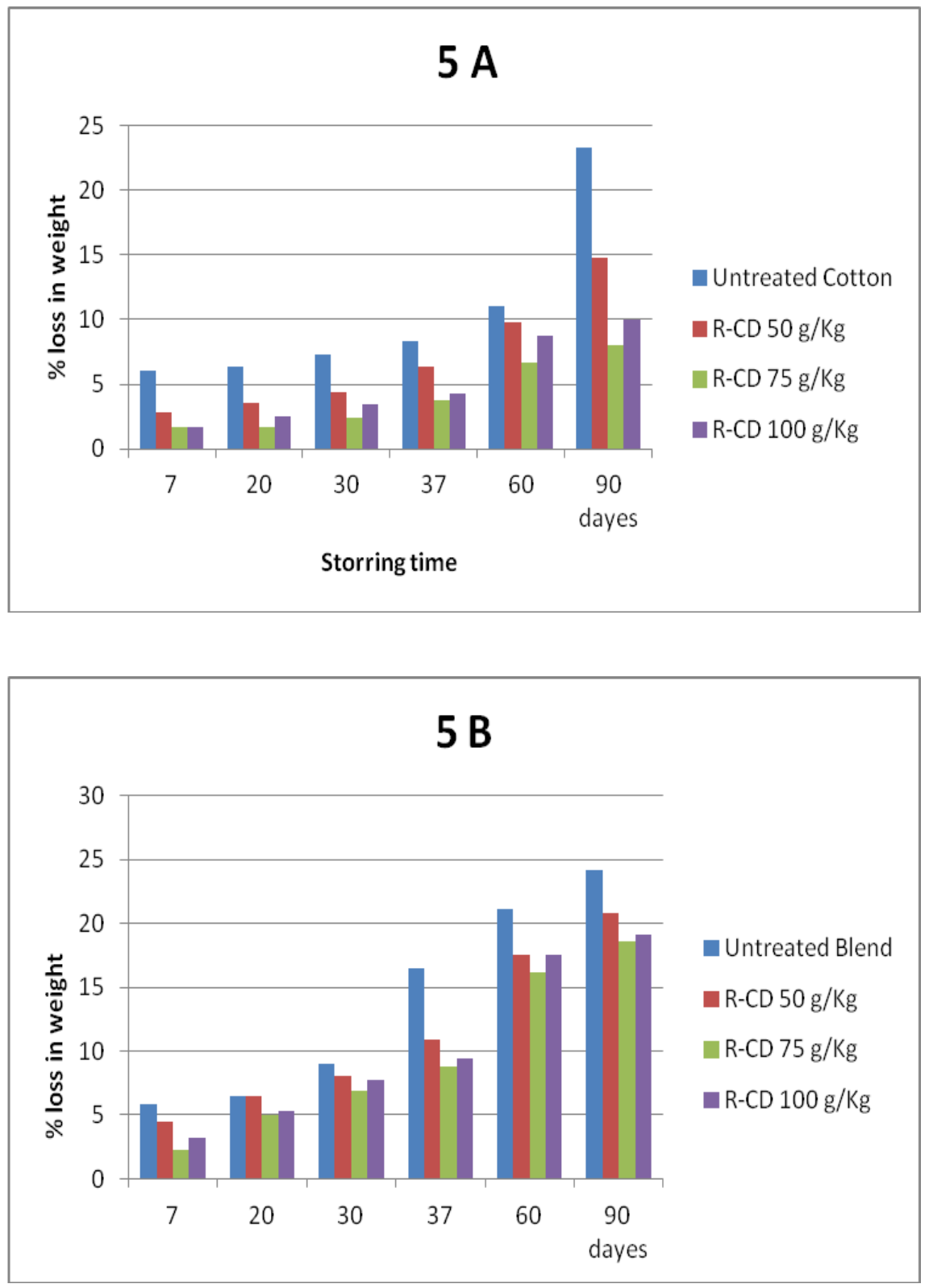

Fig. 5 (A-B). Effect of incorporation of different amounts of R-CD on the printing paste of Drimarene red CL-5B , followed by treatment with vanelline on their ability to keep fragrance upon storing. 

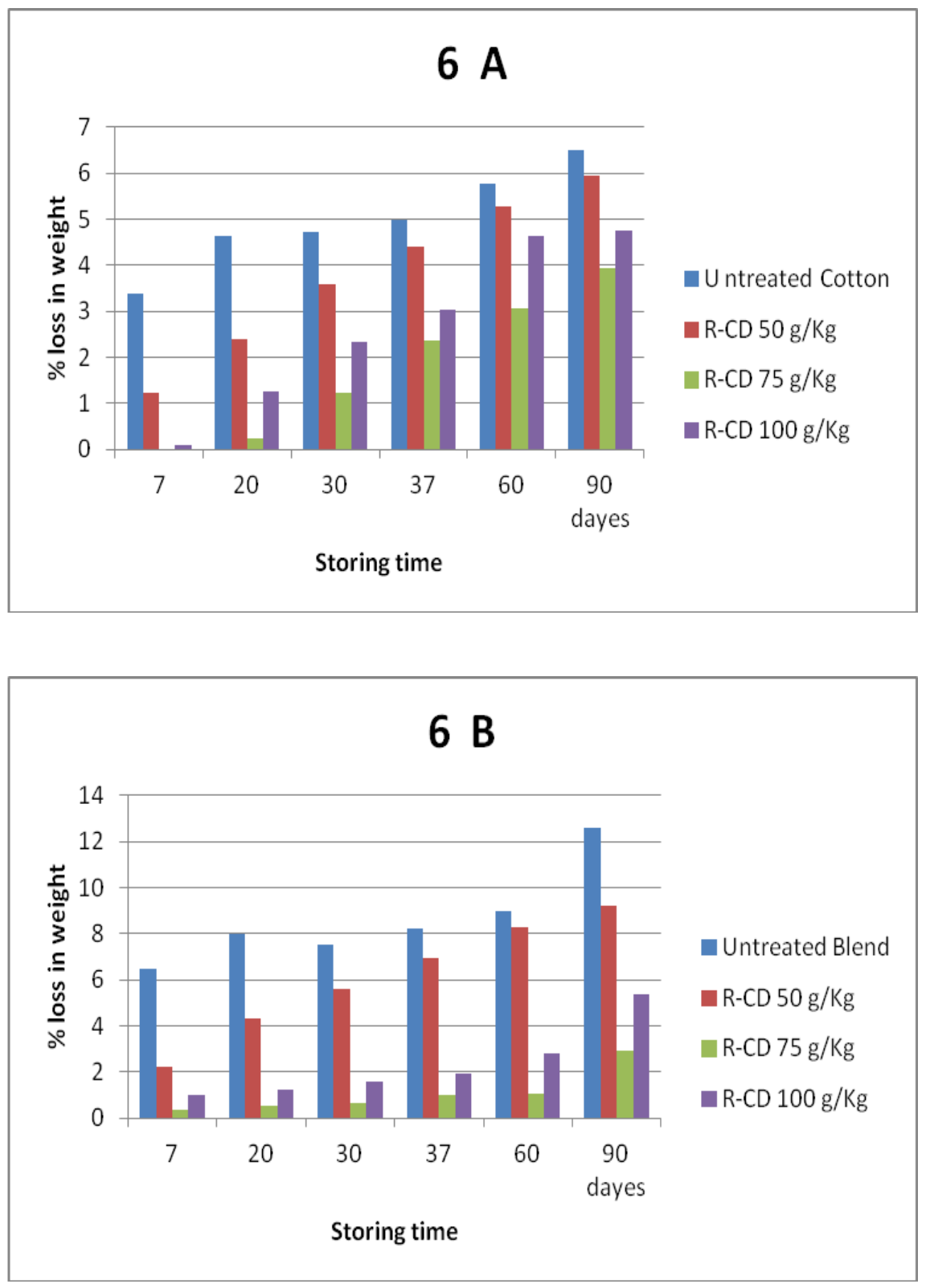

Fig. 6 (A-B). Effect of incorporation of different amounts of R-CD on the printing paste of Drimarene red CL-5B , followed by treatment with sandal oil on their ability to keep fragrance upon storing. 

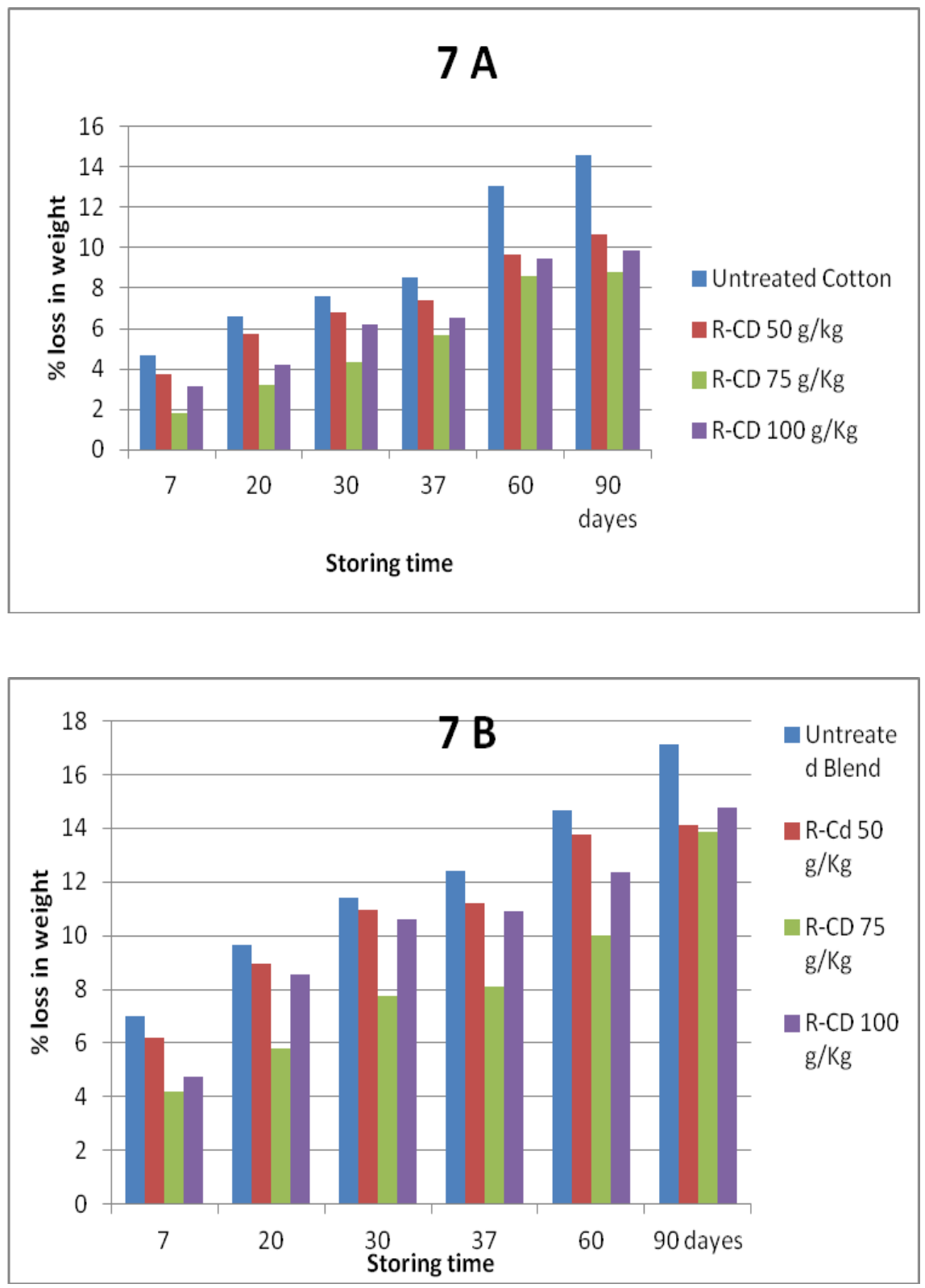

Fig. 7 (A-B). Effect of incorporation of different amounts of R-CD on the printing paste of Drimarene red CL-5B , followed by treatment with rose oil on their ability to keep fragrance upon storing. 

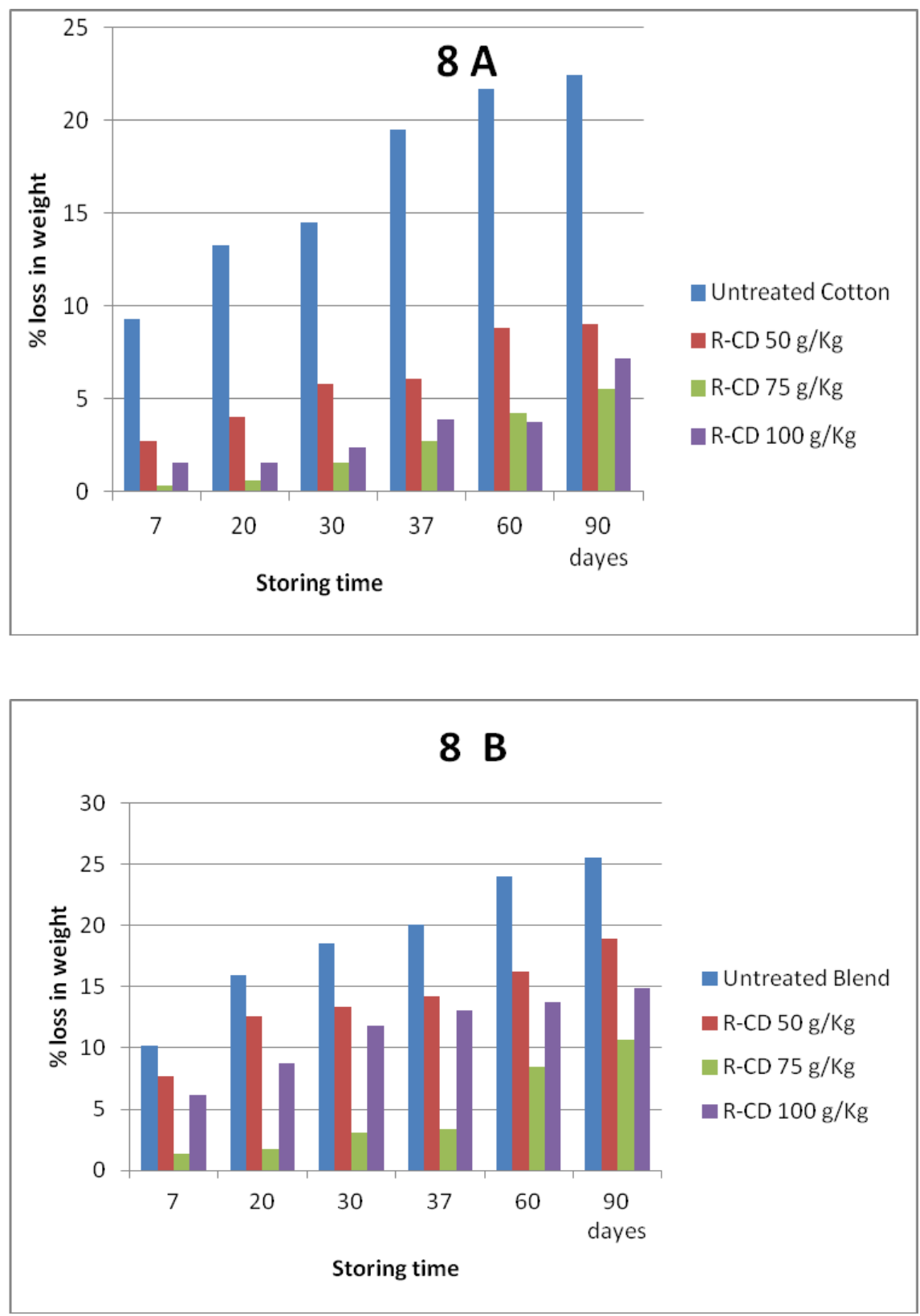

Fig. 8 (A-B). Effect of incorporation of different amounts of R-CD on the printing paste of Drimarene red CL-5B , followed by treatment with Jasmine oil on their ability to keep fragrance upon storing.

Egypt. J. Chem. 59, No.1 (2016) 


\section{Conclusion}

- R-CD could be applied to cotton or its blend with polyester fabrics to improve its printability with bifunctional reactive dyes or its ability to keep perfume fragrance via either pretreatment (pad, dry and cure) or via its incorporation in the printing paste to save time and energy.

- The extent of reaction between $\mathrm{R}-\mathrm{CD}$ and cotton expressed as $\% \mathrm{~N}$ increases by increasing its concentration from 50 to $100 \mathrm{~g} / \mathrm{l}$. While the optimum concentration in case of incorporation of R-CD to the printing paste is $75 \mathrm{~g} / \mathrm{Kg}$.

- The ability of R-CD modified cotton and cotton/polyester blend to keep fragrance increases by increasing the $\% \mathrm{~N}$ and decreases by increasing storing time up to three months and depends on the kind of the applied perfume used following the order: sandal $>$ jasmine $>$ rose $>$ vanelline oils.

- Scented ladies wear could be achieved via creation of a "host guest" functional textile for depositing fragrance. This was achieved by treatment with R-CD.

\section{References}

1. Rodrigues and Sofia, N., et al., Ind. Eng. Chem. Res. 47 (12), $4142-4147$ (2008).

2. Miuel, A. Teixeira and Oscar Rodriguer, et al., Bioengineering, Food, and Natural Products, 58 (6), 1939-1950 (2012).

3. Teixeira, C.S.N., "Microencapsulation of perfumes for Application in Textile Industry"; Ph.D., Faculty of Engineering, University of Porto. (2010).

4. Shweta. J., Journal of Textile and Apparel Technology and Management, 8 (2), (9) 1-21 (2013).

5. Environmental Protection Agency, Development Document for Effluent Limitations Guidelines and Standards for the Textile Mills; Points Source Category, EPADocument 440/1 - 79/ 022b, EPA, October (1979).

6. James M. Green and Cynthia Sokol, Using ozone to decolorize dyeing plant wastewater. American Dyestuff Reporter, 67, 50 - 51, April (1985).

7. Chavan, R.B. and Chattopadhyay, D.P., Cationization of cotton for improved dyeability. Colorage Annual, 45, 127 - 133 (1998).

8. Adham Tabba, Cationization of cotton with 2,3-epoxypropyl trimethyl ammonium chloride, Masters Thesis in Textile Chemistry, North Carolina State University (2000).

9. Kamel, M.M., Mashaly, H.M., Mansour, H.F. and Haroun, A.A., Clean dyeing technology with basic natural dye on cotton fabrics using ultrasonic technique. ManMade Textiles in India, August, 280-287 (2007). 
10. Kamel, M.M., El Zawahry, M.M.,Ahmed, N.S.E. and Abdelghaffar, F., Ultrasonic dyeing of cationized cotton fabric with natural dye Part 1: Cationization of cotton using Solfix E. Ultrasonics Sonochemistry, 16, 243-249 (2009).

11. Montazer, M., Malek, R.M.A. and Rahimi, A., Salt free reactive dyeing of cationized cotton. Fibers and Polymers, 8, 608-612 (2007).

12. Nazaria, A., Montazer, M., Moghadam, M.B. and Anary-Abbasinejad, M., Selfcleaning properties of bleached and cationized cotton using nano TiO2: A statistical approach. Carbohydrate Polymers, 83, 1119-1127 (2011).

13. Yuen, C.W.M. et al., 75 (4), 319-325 (2008).

14. Bidoki, S.M. et al., AATCC Review, 5 (6), 11-14 (2005).

15. Cole, J. O. and Parks, C. R., Ind. Eng. Chem. Anal. Ed. 18, 61 (1946).

16. Judd, D. B. and Wyszecki, G., Colour in Business, Science and Industry, $3^{\text {nd }}$ ed., John Wiley and Sons (1975).

17. The Society of Dyers and Colorists, "Standard methods for Assessment of Color Fastness of Textiles" Third Report of the Fastness Tests Coordinating Committee, Yorkshire, England p. 24,37,63 and 71 (1955).

18. Gabr, N.G.M., M.Sc. Thesis, Faculty of Applied Arts, Helwan University, Egypt (2013).

(Received 7/12/2015;

accepted 26/1/2016) 


\title{
طباعة و تحوير أقمشة وظيفية معطرة بخلق مراكز فعالة للإحتفاظ
} بالمواد العطرية وتير أحية

\author{
جاكلين إبراهيم ، عائشة نصر و نهاد جبر الفير

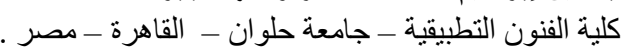

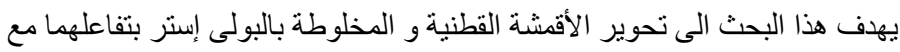

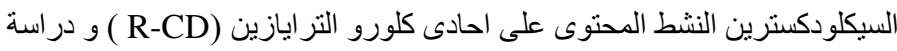

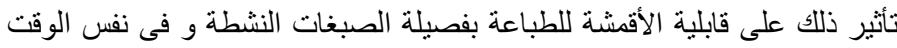

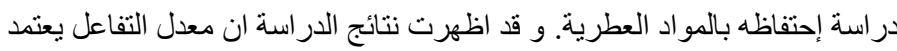

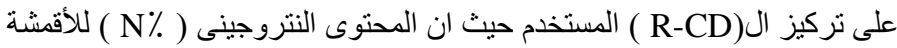

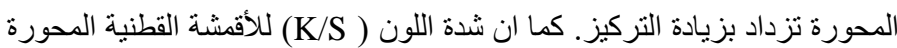

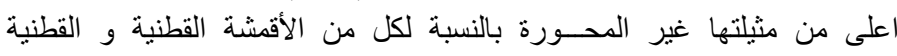

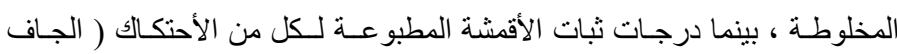

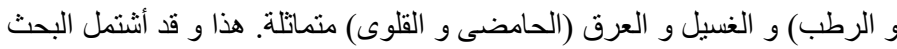

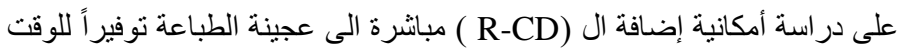

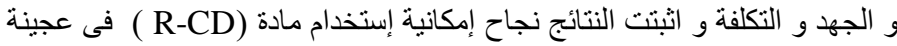

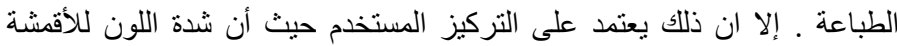

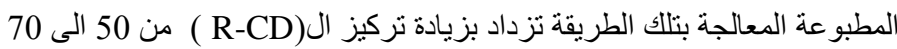

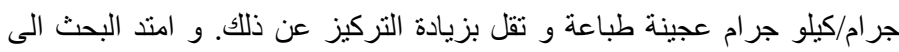

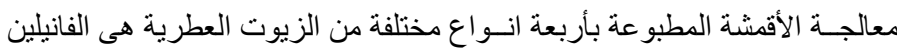

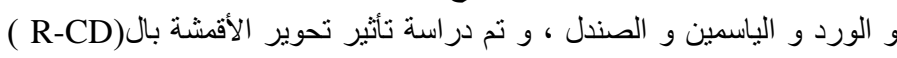

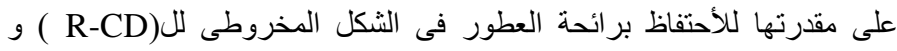

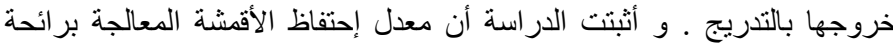

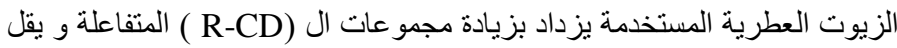

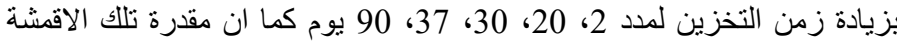

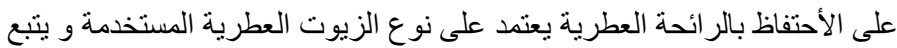

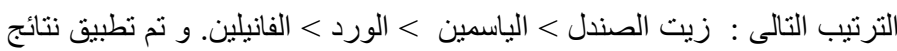

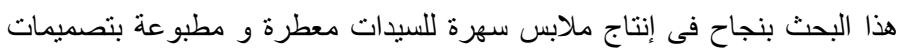

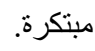

